\title{
Characterizing Recombination in CdTe Solar Cells with Time- Resolved Photoluminescence
}

Conference Paper NREL/CP-520-39926

May 2006

\section{Preprint}

W.K. Metzger, M.J. Romero, P. Dippo, and M. Young

Presented at the 2006 IEEE $4^{\text {th }}$ World Conference on Photovoltaic Energy Conversion (WCPEC-4) Waikoloa, Hawaii May 7-12, 2006
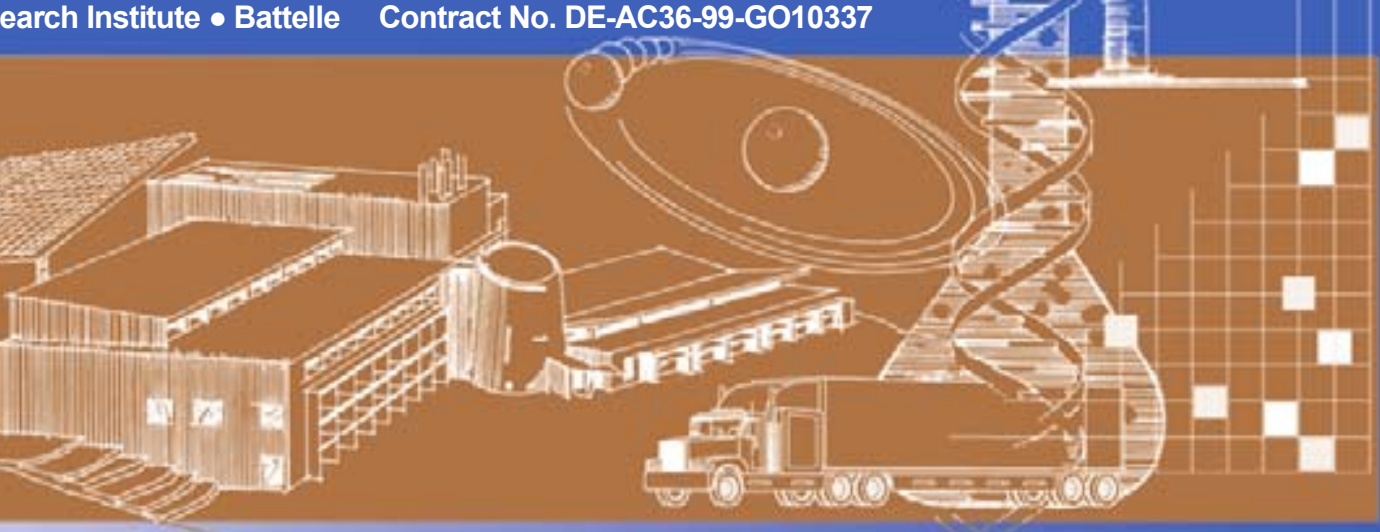


\section{NOTICE}

The submitted manuscript has been offered by an employee of the Midwest Research Institute (MRI), a contractor of the US Government under Contract No. DE-AC36-99G010337. Accordingly, the US Government and MRI retain a nonexclusive royalty-free license to publish or reproduce the published form of this contribution, or allow others to do so, for US Government purposes.

This report was prepared as an account of work sponsored by an agency of the United States government. Neither the United States government nor any agency thereof, nor any of their employees, makes any warranty, express or implied, or assumes any legal liability or responsibility for the accuracy, completeness, or usefulness of any information, apparatus, product, or process disclosed, or represents that its use would not infringe privately owned rights. Reference herein to any specific commercial product, process, or service by trade name, trademark, manufacturer, or otherwise does not necessarily constitute or imply its endorsement, recommendation, or favoring by the United States government or any agency thereof. The views and opinions of authors expressed herein do not necessarily state or reflect those of the United States government or any agency thereof.

Available electronically at http://www.osti.gov/bridge

Available for a processing fee to U.S. Department of Energy and its contractors, in paper, from:

U.S. Department of Energy

Office of Scientific and Technical Information

P.O. Box 62

Oak Ridge, TN 37831-0062

phone: 865.576 .8401

fax: 865.576 .5728

email: mailto:reports@adonis.osti.gov

Available for sale to the public, in paper, from:

U.S. Department of Commerce

National Technical Information Service

5285 Port Royal Road

Springfield, VA 22161

phone: 800.553 .6847

fax: 703.605.6900

email: orders@ntis.fedworld.gov

online ordering: http://www.ntis.gov/ordering.htm 


\title{
CHARACTERIZING RECOMBINATION IN CdTe SOLAR CELLS WITH TIME-RESOLVED PHOTOLUMINESCENCE*
}

\author{
W.K. Metzger, M.J. Romero, P. Dippo, and M. Young \\ National Renewable Energy Laboratory, 1617 Cole Blvd., Golden, CO 80401 USA
}

\begin{abstract}
Time-resolved photoluminescence (TRPL) computer simulations demonstrate that under certain experimental conditions it is possible to assess recombination in CdTe solar cells in spite of the junction. This is supported by experimental findings that open-circuit voltage $\left(V_{o c}\right)$ is dependent on lifetime in a manner consistent with device theory. Measurements on inverted structures show that the $\mathrm{CdCl}_{2}$ treatment significantly reduces recombination in the CdTe layer without $\mathrm{S}$ diffusion. However, $\mathrm{S}$ diffusion is required for lifetimes comparable to those observed in high-efficiency solar cells. The results indicate that substrate solar cells can be fabricated with recombination lifetimes similar to superstrate cells.
\end{abstract}

\section{INTRODUCTION}

Solar cell technology requires the ability to understand and manipulate transport and recombination processes in microstructures. A standard method to characterize recombination in semiconductor materials is to inject excess carriers into confinement devices such as double heterostructures. Optical excitation is produced with a fast laser pulse, and one observes the subsequent decay in photoluminescence (PL), photoconductivity, or any other physical property related to the excess carrier density. The confinement limits excess carriers to the material under investigation, simplifies analysis, and can help control surface recombination.

However, polycrystalline CdTe cannot be incorporated into a confining double heterostructure suitable for recombination studies, and completed devices may have recombination properties due to interface, material, and growth issues that cannot be observed in a test structure. Recombination measurements in the presence of the CdTe/CdS junction are needed, but interpretation is complicated by the carrier dynamics introduced. The electric field can quickly alter the spatial profiles of the excess electrons and holes, thereby distorting recombination rates and making analysis complex.

In this paper, we briefly describe three separate TRPL studies which together help characterize recombination in CdTe solar cells. First, we use computational modeling to examine if and under what experimental conditions TRPL on CdTe solar cells can give meaningful values of the recombination rate in the
CdTe layer. We then compare experimental TRPL results on CdTe solar cells with device performance to see if measured lifetime values are consistent with basic theory and computer models. Finally, we examine TRPL on samples before and after the CdTe/CdS junction is formed.

CdTe solar cells are usually grown by depositing $\mathrm{CdTe}$ on $\mathrm{CdS} / \mathrm{SnO}_{2} /$ glass substrates. In this superstrate configuration, the CdTe layer cannot be measured without the influence of the $\mathrm{CdTe} / \mathrm{CdS}$ junction. Furthermore, when $\mathrm{CdS}$ is present, the $\mathrm{CdCl}_{2}$ treatment required for reasonably efficient $\mathrm{CdTe}$ solar cells induces $\mathrm{S}$ diffusion from the CdS layer into the CdTe. So the recombination effects of the $\mathrm{CdCl}_{2}$ treatment on bulk CdTe cannot be separated out from interfacial $\mathrm{S}$ diffusion. To observe the role of $\mathrm{CdCl}_{2}$ treatment on $\mathrm{CdTe}$, without the junction or $\mathrm{S}$ diffusion, CdTe was deposited on glass $/ \mathrm{SnO}_{2}$ substrates and PL lifetimes were measured on samples with and without a $\mathrm{CdCl}_{2}$ treatment. To observe the effects of the junction and $\mathrm{S}$ diffusion, CdS was subsequently deposited and half of the samples were $\mathrm{CdCl}_{2}$ treated.

\section{SIMULATION AND EXPERIMENT}

In the TRPL simulations, a $500-\mathrm{fs}$ laser pulse injects carriers into a structure consisting of $500-\mathrm{nm} \mathrm{SnO}_{2}, 80-\mathrm{nm}$ $\mathrm{CdS}$, and $8-\mu \mathrm{m} \mathrm{CdTe}$. The light has a wavelength of 600 $\mathrm{nm}$, penetrates the $\mathrm{SnO}_{2}$ and the CdS layers, and generates carriers primarily within the first $500 \mathrm{~nm}$ of the $\mathrm{CdTe} / \mathrm{CdS}$ metallurgical junction. The computer tracks the generation, drift, diffusion, and recombination of excess carriers as a function of time. From this, we are able to generate simulated PL decay curves as described in detail in reference 1 . The material parameters are taken from conventional models and experimental estimates [2], however, the electron and hole lifetimes in the CdTe region are fixed at 20 ns. By extracting the PL decay time from the simulated curves, we can determine if TRPL measurements on a completed solar cell can properly assess the recombination lifetime assigned to the CdTe layer. The impact of the junction on PL decay is easily visualized by comparing the PL decay curves generated on a complete solar cell structure with PL decay curves generated from a solitary CdTe layer.

Real TRPL measurements were performed using the photoexcitation generated by a mode-locked, cavitydumped dye laser operating at a repetition rate of $1 \mathrm{MHz}$ with a wavelength of $630 \mathrm{~nm}$ and a pulse width of $5 \mathrm{ps}$.

* This work has been authored by an employee or employees of the Midwest Research Institute under Contract No. DE-AC36-99GO10337 with the U.S. Department of Energy. The United States Government retains and the publisher, by accepting the article for publication, acknowledges that the United States Government retains a non-exclusive, paid-up,

irrevocable, worldwide license to publish or reproduce the published form of this work or allow others to do so, for United States Government purposes. 
The laser spot size was about $1 \mathrm{~mm}$ in diameter, and the average power was $10 \mathrm{~mW}$. PL was passed through a spectrometer to a photomultiplier tube. The overall system resolution was about 20 ps using deconvolution and standard time-correlated single-photon counting [3]. All measurements were performed at room temperature. Reference 4 gives a detailed description of TRPL measurements and analysis on CdTe solar cells.

To grow CdTe films from 2.3 to $8.2 \mu \mathrm{m}$ thick directly on $\mathrm{SnO}_{2}$ /Corning 7059 glass substrates, a lowtemperature nucleation thermal profile during the closespaced sublimation (CSS) process was used [5]. CdS films about $80 \mathrm{~nm}$ thick were grown using the chemicalbath deposition (CBD) technique. $\mathrm{CdCl}_{2}$ treatments were performed by suspending either $\mathrm{CdTe} / \mathrm{SnO}_{2} /$ glass or $\mathrm{CdS} / \mathrm{CdTe} / \mathrm{SnO}_{2} /$ glass samples directly over a $\mathrm{CdCl}_{2-}$ coated source plate in a CSS configuration; the anneal temperature was $400^{\circ} \mathrm{C}$ and the ambient consisted of 100 torr oxygen and 400 torr helium.

A total of eight samples were grown and are labeled A through $\mathrm{H}$. The CdTe layers in samples $A, B$, and $C$ were $2.3,3.2$, and $4.4 \mu \mathrm{m}$ thick, respectively; the CdTe layer in samples $\mathrm{D}$ through $\mathrm{H}$ were all about $8 \mu \mathrm{m}$ thick. After depositing the CdTe, each sample was divided into two pieces: one piece was $\mathrm{CdCl}_{2}$ treated, and the other was not. After performing lifetime measurements, CdS was deposited on samples $A$ through $G$ (but not $H$ ). These samples were again divided into two pieces, and only one piece was $\mathrm{CdCl}_{2}$ treated. As a result, there are six measurement categories. One letter, $\mathrm{Y}$ or $\mathrm{N}$, means the measurement was performed on a sample that did not yet have a CdS layer, and either $\operatorname{did}(\mathrm{Y})$ or $\operatorname{did} \operatorname{not}(\mathrm{N})$ have a $\mathrm{CdCl}_{2}$ treatment. Two letters, $\mathrm{YY}, \mathrm{YN}, \mathrm{NY}$, and $\mathrm{NN}$, means the measurement was performed on a sample that did have a CdS layer. The first of the two letters refers to whether the sample $\operatorname{did}(\mathrm{Y})$ or $\operatorname{did}$ not $(\mathrm{N})$ have a $\mathrm{CdCl}_{2}$ treatment prior to the CdS deposition, and the second letter refers to whether the sample did $(\mathrm{Y})$ or did not $(\mathrm{N})$ have a $\mathrm{CdCl}_{2}$ treatment after the $\mathrm{CdS}$ deposition. Sample $\mathrm{E}$ ( $\mathrm{YN}$ and $\mathrm{NN}$ ) received a heat treatment equivalent to the $\mathrm{CdCl}_{2}$ treatment, except that $\mathrm{CdCl}_{2}$ was absent.

\section{RESULTS AND DISCUSSION}

The TRPL computer simulations provide snapshots of the electron and hole concentrations at discrete times before and after a laser pulse on a complete CdTe solar cell with an 8- $\mu \mathrm{m}$ CdTe layer. For clarity, Fig. 1 focuses on the $\mathrm{CdTe}$ region beginning at the $\mathrm{CdTe} / \mathrm{CdS}$ interface (positioned at $0 \mu \mathrm{m}$ in the graph) and ending $3 \mu \mathrm{m}$ into the CdTe region. In the experiments and simulations, $\mathrm{PL}$ is collected only from the CdTe region. For easy reference, we will define $\mathrm{P}_{0}$ as the injection level that corresponds to $8.8 \times 10^{11}$ photons $/ \mathrm{cm}^{2}$ incident on the CdTe layer.

Fig. 1a shows the equilibrium and excess carrier distributions for an injection level of $0.01 \mathrm{P}_{0}$. The laser pulse generates excess electrons and holes in a Beer's law distribution. Just 1 ns later, long before bulk recombination is prevalent, the electrons and holes have been separated out by the electric field.
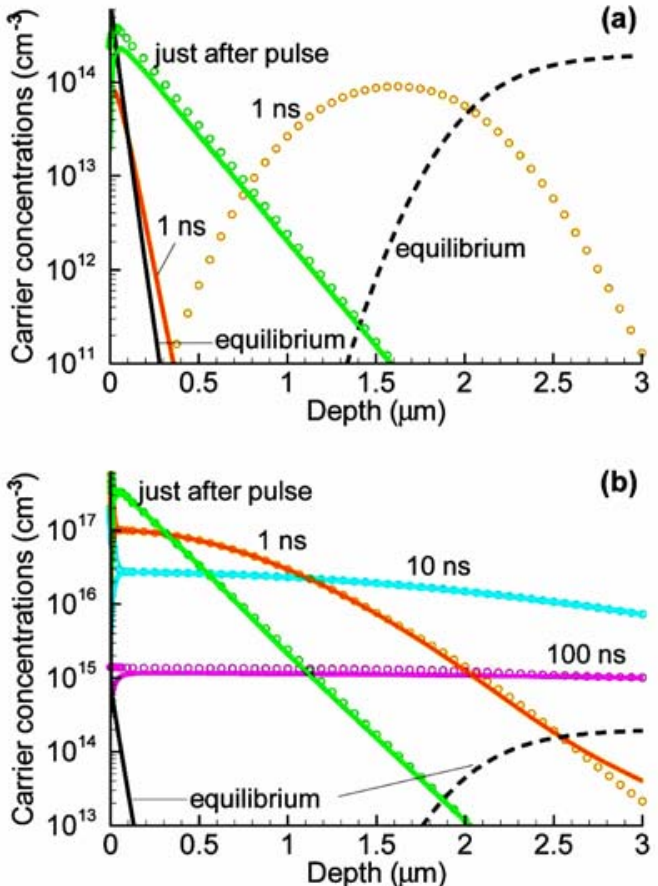

Fig. 1. Excess electron and hole concentrations at given times after a laser pulse for an injection level of (a) $0.01 \mathrm{P}_{0}$ and (b) $10 \mathrm{P}_{0}$. The solid lines represent the electron concentration; the dashed line or circles represent the hole concentration.

For an injection level of $10 \mathrm{P}_{0}$ (Fig. 1b), the dynamics are very different. Photoinjected carriers overwhelm the equilibrium carrier concentrations and screen the equilibrium electric field. As a result, electrons and holes diffuse throughout the CdTe layer together, and there is very little charge separation. This is identical to the behavior one would expect in an ideal CdTe layer without any junction.

So the degree of charge separation, and hence its effect on TRPL measurements, is a function of injection level. Figure 2 illustrates this by comparing simulated TRPL curves from an ideal CdTe layer (no junction) with TRPL curves from a CdTe solar cell (with junction) at 4 different injection levels. The radiative recombination rate per unit volume, $R_{\text {rad, }}$, is given by

$$
R_{\text {rad }}(t)=B\left[p(\mathbf{r}, t) n(\mathbf{r}, t)-p_{0}(\mathbf{r}) n_{0}(\mathbf{r})\right]
$$

where $B$ is the radiative coefficient, $p$ and $n$ are the total hole and electron concentrations, and $p_{0}$ and $n_{0}$ are the equilibrium hole and electron concentrations, respectively. The PL intensity depends on the spatial overlap of excess holes and electrons. At the lowest injection level shown, $0.01 \mathrm{P}_{0}$, the junction quickly separates electrons and holes and the $\mathrm{PL}$ intensity decays at a rate determined by charge separation, not recombination. In high injection conditions, the field is screened and the PL intensity initially decays at a rate determined primarily by recombination. After enough excess carriers recombine, the equilibrium field eventually recovers and charge separation again emerges (not shown). However, in high 

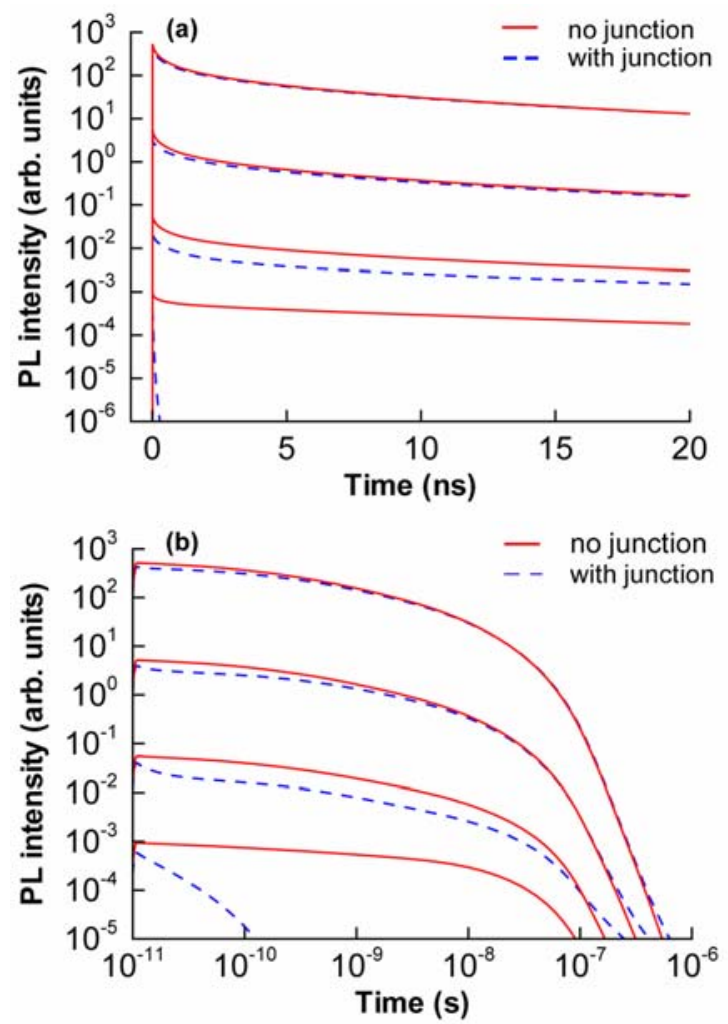

Fig. 2. PL decay curves for injection levels of 0.01 , $0.1,1$, and $10 P_{o}$, respectively, on log-linear and loglog scales.

injection, this occurs beyond the dynamic range of most TRPL measurements and recombination will dominate most of the PL decay signal. Consequently, as the injection level is increased (see Fig. 2), the PL curves from a completed CdTe solar cell overlap those from an ideal CdTe layer, until it is as though the junction is not there. Fitting these high injection PL decay curves reproduces the lifetime that was assigned to the CdTe layer.

Actual TRPL measurements cannot explore the same parameter space as the simulations. CdTe has poor radiative efficiency and very low doping. So in practice, the TRPL experiment is not sufficiently sensitive to acquire a signal when the injection levels are low enough that charge separation is dominant. The experimental cutoff is typically around $0.5 \mathrm{P}_{\mathrm{o}}$.

In high-injection conditions, the modeling predictions are consistent with experimental results. In general, the charge separation time should be negatively correlated with device performance. For example, increased doping and mobility lead to faster charge separation, but superior device performance. On the other hand, the recombination lifetime should be positively correlated with device performance. For injection levels corresponding to about 1 to $10 \mathrm{P}_{0}$, room-temperature TRPL measurements on more than 80 completed CdTe solar cell devices fabricated under diverse conditions show a strong correlation with $V_{\text {oc }}$ (see Fig. 3). A detailed account of sample preparation, measurements, and analysis are provided in reference 4.

Device theory gives specific predictions for how $V_{\text {oc }}$ and other device parameters should vary with recombination lifetime. Current-voltage characteristics under AM1.5 illumination were modeled using the same device structure and material parameters as the TRPL simulations. However, here the lifetimes were adjusted by inserting a midgap trap with a density of $2 \times 10^{14} \mathrm{~cm}^{-3}$ and altering the electron and hole capture cross-sections, which were set equal to one another. Figure 3 shows that the lifetime values are consistent with $\mathrm{CdTe}$ device models, experimental observations, and standard device physics. In spite of the junction, TRPL is a technique capable of quantitatively assessing recombination in the interface and depletion region, which is driving device performance.

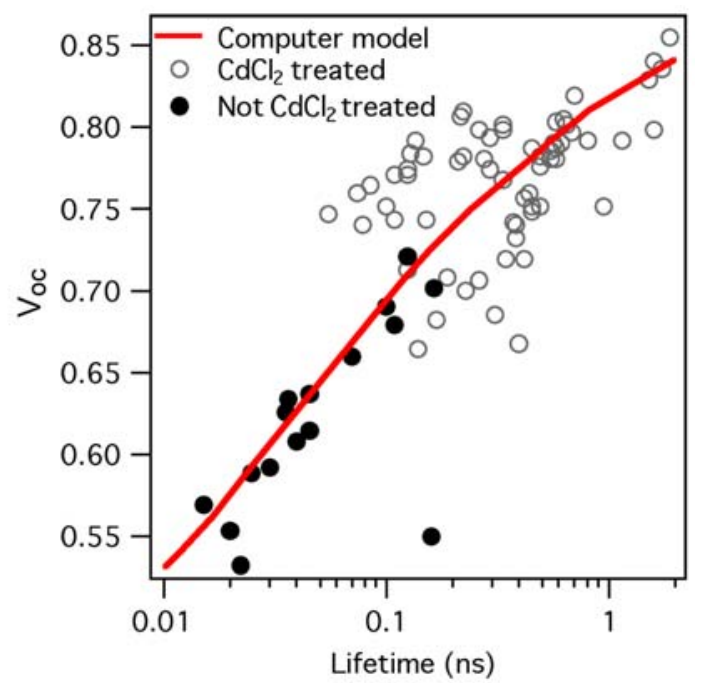

Fig. 3. $V_{o c}$ vs. PL lifetime data compiled from seven separate studies that used different growth conditions [4].

By growing glass $/ \mathrm{SnO}_{2} / \mathrm{CdTe}$ and glass $/ \mathrm{SnO}_{2} / \mathrm{CdTe} / \mathrm{CdS}$ structures, we are able to distinguish and quantify to some degree the roles of junction formation, $\mathrm{S}$ diffusion, and the $\mathrm{CdCl}_{2}$ treatment on recombination. Reference 4 gives a detailed description of TRPL measurements and analysis on completed CdTe solar cells. In this study, a similar injection level (about 5 $\mathrm{P}_{0}$ ) was used, and the fits were again done by fitting a single exponential through the initial section of the decay for direct comparison. When necessary, the system response was deconvoluted from the measured PL decay [3]. The monochromator was tuned to the bandgap luminescence, and all the lifetime data were measured at room temperature. So the contribution of recombination from sub-bandgap features frequently observed in very low-temperature PL, such as donor-acceptor pairs and excitons, is negligible. Overall, the gross recombination characteristics of the inverted structures with or without the CdS layer are very similar to those observed in the superstrate devices. The radiative efficiency is about the same; the lifetimes range from 50 ps to $1 \mathrm{~ns}$; and the lifetimes do not vary appreciably with injection. These 
observations are inconsistent with strong radiative recombination or Auger recombination. The dominant recombination mechanisms are nonradiative and associated with Shockley-Read-Hall and surface recombination. The initial decay may reflect a mixture of interface recombination, grain-boundary recombination, bulk recombination, and transients caused by carrier kinetics. There is not enough information to accurately quantify the individual contributions, but device performance will be affected by the aggregate recombination rate.

Figure 4 illustrates the PL lifetimes for samples $\mathrm{A}-\mathrm{H}$ with and without $\mathrm{CdCl}_{2}$ treatments before and after CdS deposition. The PL is excited mostly within $1 \mu \mathrm{m}$ of the incident surface. First, we look at measurements where the laser light is incident through the glass. Modeling indicates that for the applied injection levels, charge separation at the $\mathrm{SnO}_{2} / \mathrm{CdTe}$ interface or grain boundaries does not significantly affect the measured lifetime. Asreceived samples $(N)$ have lifetimes less than 100 ps. When this layer is $\mathrm{CdCl}_{2}$ treated $(\mathrm{Y})$, the treatment penetrates the entire CdTe layer and the lifetime increases to values between 350 and 600 ps. The addition of CdS (NN, YN, NY, and YY) predictably has no effect on the lifetime at the bottom of the CdTe layer. The impact of the $\mathrm{CdCl}_{2}$ treatment is the same with or without the CdS layer, so $S$ diffusion does not affect recombination throughout the entire CdTe region.

The trends are different when the laser light is incident on top of the cell. As-received layers have lifetimes that vary from 100 to 300 ps and are correlated with thickness. The $\mathrm{CdCl}_{2}$ treatment preferentially improves the lifetimes of thin cells, perhaps by preferentially affecting the small grains associated with thinner cells [6]. The addition of CdS without any further $\mathrm{CdCl}_{2}$ treatment ( $\mathrm{NN}$ and $\mathrm{YN}$ ) also increases the lifetime. This cannot be explained by charge separation, and

(a) Light incident through the glass

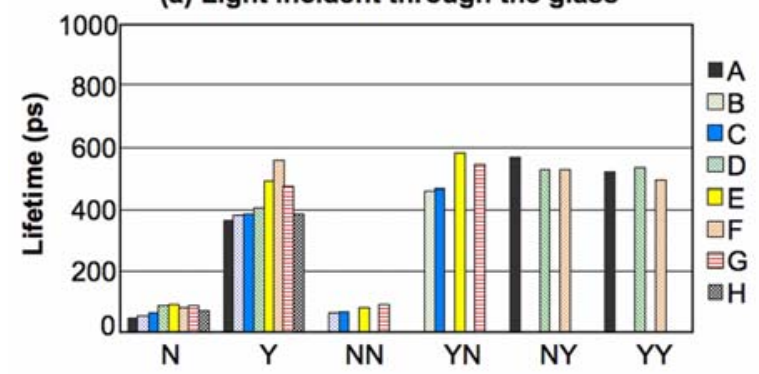

(b) Light incident through the top of the cell

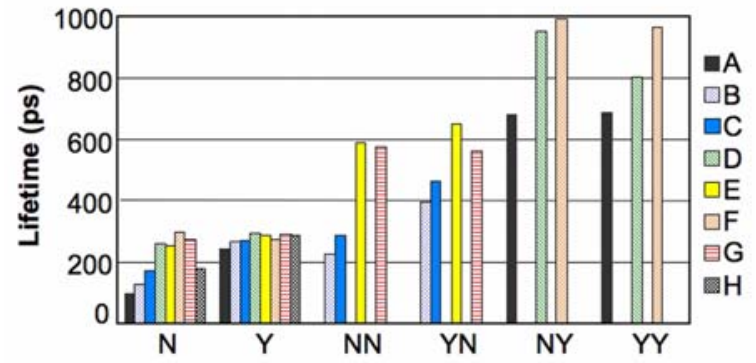

Fig. 4. Lifetimes for samples $\mathrm{A}-\mathrm{H}$ after different processing and treatment steps. suggests that the CdS layer may passivate the free CdTe surface. Secondary-ion mass spectrometry measurements indicate that when a CdS layer is present, the $\mathrm{CdCl}_{2}$ treatment causes $S$ diffusion [5]. The longest lifetimes, which are commensurate with those measured in highquality CdTe solar cells, are only achieved when there is significant $\mathrm{S}$ diffusion.

\section{CONCLUSIONS}

Computational modeling shows that TRPL measurements can assess recombination in CdTe solar cells in high-injection conditions. This is supported by measurements on more than 80 samples, which indicate that the open-circuit voltage is dependent on lifetime in a manner consistent with device theory. Measurements on inverted structures indicate that the $\mathrm{CdCl}_{2}$ treatment, without any $S$ present, significantly reduces recombination. However, $S$ diffusion is required for lifetimes comparable to those observed in high-efficiency solar cells. The results indicate that substrate solar cells can be fabricated with recombination characteristics similar to those of superstrate cells.

\section{ACKNOWLEDGEMENTS}

This work is supported under DOE Contract No. DEAC36-99G010337. We would also like to acknowledge D. Albin.

\section{REFERENCES}

[1] W.K. Metzger, R.K. Ahrenkiel, J. Dashdorj, and D. Friedman, Phys. Rev. B 71, 035301 (2005).

[2] M. Gloeckler, A.L. Fahrenbruch, and J.R.Sites, in Proceedings of $3^{\text {rd }}$ World Conference on Photovoltaic Energy Conversion (2003), p. 491.

[3] D.V. O'Connor and D. Phillips, Time Correlated Single Photon Counting, Academic Press:San Diego, 1984.

[4] W.K. Metzger, D.Albin, D. Levi, P. Sheldon, X. Li, B.M. Keyes, and R.K. Ahrenkiel, J. Appl. Phys. 94, 3549 (2003).

[5] W.K. Metzger, D. Albin, M.J. Romero, P. Dippo, and M. Young, J. Appl. Phys. 99, in press (2006).

[6] H.R. Moutinho, R.G. Dhere, M.M. Al-Jassim, D.H. Levi, and L.L. Kazmerski, J. Vac. Sci. Technol. A 17,1793 (1999). 